\title{
Genome-Wide Association Study Reveals Genetic Architecture of Septoria Tritici Blotch Resistance in a Historic Landrace Collection
}

\section{Anik Dutta}

ETH Zürich: Eidgenossische Technische Hochschule Zurich https://orcid.org/0000-0003-1196-6305

\section{Daniel Croll}

Universite de Neuchatel

\section{Bruce A. McDonald}

ETH Zurich: Eidgenossische Technische Hochschule Zurich

Simon G. Krattinger ( $\nabla$ simon.krattinger@kaust.edu.sa )

King Abdullah University of Science and Technology

\section{Research Article}

Keywords: wheat, landrace, disease resistance, septoria tritici blotch, Zymoseptoria tritici, germplasm collection

Posted Date: February 8th, 2021

DOI: https://doi.org/10.21203/rs.3.rs-172173/v1

License: (c) (i) This work is licensed under a Creative Commons Attribution 4.0 International License. Read Full License 
54 Genome-wide association study reveals genetic architecture of septoria tritici 55 blotch resistance in a historic landrace collection

56

57

58

59 'Plant Pathology, Institute of Integrative Biology, ETH Zurich, Zurich, Switzerland

60 '2Laboratory of Evolutionary Genetics, Institute of Biology, University of Neuchâtel, Neuchâtel,

61 Switzerland

$62{ }^{3}$ Center for Desert Agriculture, Biological and Environmental Science \& Engineering Division

63 (BESE), King Abdullah University of Science and Technology (KAUST), Thuwal, Saudi Arabia

64

65 "Corresponding author: Simon G. Krattinger; E-mail: simon.krattinger@kaust.edu.sa

66

67

68

69

70

71

72

73

74

75

76

77

78

79

80

81

82

83

84 
87 Septoria tritici blotch (STB), caused by the fungus Zymoseptoria tritici, is a major constraint in

88 global wheat production. The lack of genetic diversity in modern elite wheat cultivars largely

89 hinders the improvement of STB resistance. Wheat landraces are reservoirs of untapped genetic

90 diversity, which can be exploited to find novel STB resistance genes or alleles. Here, we

91 characterized 188 Swiss wheat landraces for resistance to STB using four Swiss Z. tritici isolates.

92 We used a genome-wide association study (GWAS) to identify genetic variants associated with

93 the amount of lesion and pycnidia production by the fungus. The majority of the landraces were

94 highly resistant for both traits to the isolate 1E4, indicating a gene-for-gene relationship, while

95 higher phenotypic variability was observed against other isolates. GWAS detected a significant

$96 \mathrm{SNP}$ on chromosome 3A that was associated with both traits in the isolate 1E4. The resistance

97 response against 1E4 was likely controlled by the Stb6 gene. Sanger sequencing revealed that the

98 majority of these $\sim 100$-year-old landraces carry the Stb6 resistance allele. This indicates the 99 importance of this gene in Switzerland during the early 1900s for disease control in the field. Our

100 study demonstrates the importance of characterizing historic landrace collections for STB 101 resistance to provide valuable information on resistance variability and contributing alleles. This 102 will help breeders in the future to make decisions on integrating such germplasms in STB 103 resistance breeding.

104

105 Keywords: wheat, landrace, disease resistance, septoria tritici blotch, Zymoseptoria tritici, 106 germplasm collection. 
Wheat (Triticum aestivum L.) is a staple crop that plays an important role in meeting the growing demand for food of a growing global population (UN, 2015). However, the current rate of global wheat yield increase is insufficient to ensure food security (Ray et al. 2013). This is partly due to continuous threats of diseases on wheat production caused by rapidly evolving pathogens. Septoria tritici blotch (STB) is considered as a major fungal foliar disease of wheat worldwide, especially in Europe, causing yield losses of up to 50\% in severe epidemics (Jørgensen et al. 2014; Fones and Gurr, 2015; Savary et al. 2019). STB is caused by the hemibiotrophic fungus Zymoseptoria tritici, which has a mixed reproductive system producing airborne sexual ascospores and asexual fruiting bodies called pycnidia (McDonald and Mundt 2016). The fungus causes necrotic lesions on leaves that reduce the photosynthetic activity, leading to yield loss. Pycnidia produced within lesions generate millions of spores that are dispersed mainly by rain splash to nearby plants and wheat fields. Several cycles of sexual and asexual reproduction during a growing season (Karisto et al. 2018) facilitates the maintenance of high genetic diversity with high effective population size and significant gene flow (Zhan, Pettway, and McDonald 2003). Cultivation of resistant wheat varieties and applications of fungicides are the major approaches used to minimize yield loss. However, the fungus can rapidly adapt to these control measures owing to its high evolutionary potential, monocropping with single resistant cultivars, and intensive use of fungicides (Cowger, Hoffer, and Mundt 2000; Estep et al. 2015; Hayes et al. 2016). Because fungicide applications are costly and detrimental to the environment (Fones and Gurr, 2015), finding novel STB resistance genes or alleles, and introgression into modern cultivars remains the most effective and environmentally sound approach to control STB.

140 STB resistance can be both quantitative (i.e., controlled by several small effect loci) and qualitative 141 (i.e., controlled by a major gene) under field conditions depending on the cultivar-isolate 142 interactions (Brown et al. 2015). To date, 21 qualitative STB resistance genes and 167 genomic 143 regions harboring quantitative trait loci (QTL) conferring STB resistance have been identified and 144 mapped (Brown et al., 2015; Yates et al. 2019). Qualitative resistance is mostly active against $Z$. 145 tritici isolates carrying corresponding avirulence genes. Although such genes are often prioritized in breeding programs due to their large phenotypic effects, their resistance is easily overcome by 
147 rapidly evolving pathogens (Cowger, Hoffer, and Mundt 2000; Ponomarenko et al. 2011). Owing

148 to high levels of genetic variability in plant pathogen populations, resistance genes are often under 149 diversifying selection (Jacob, Vernaldi, and Maekawa 2013). For example, a differential resistance 150 pattern of different alleles of $\operatorname{Pm} 3$ (a wheat powdery mildew resistance gene) was observed against 151 a range of powdery mildew isolates (Bhullar et al. 2009, 2010). Recently, Stb6, a major STB 152 resistance gene that is predominant in modern and old wheat cultivars, has been cloned and found 153 to possess a single functional resistance allele and several susceptible alleles (Saintenac et al. 154 2018). Stb6 encodes a wall-associated receptor kinase (WAK) and follows a gene-for-gene 155 relationship with the corresponding avirulence gene AvrStb6 (Zhong et al. 2017). However, it 156 remains unknown whether wheat gene bank materials such as landraces harbor any novel Stb6 157 resistance alleles and how such alleles would contribute to STB resistance. Given the advancement 158 in modern genomics, it has become feasible to genotype large collections of gene bank materials 159 to discover genes of interest and rescue lost allelic forms of genes controlling key agronomic traits 160 (Milner et al. 2019; Liu et al. 2021). Together with precision disease phenotyping and genetic 161 information, phenotypic contributions of different alleles can be dissected and novel alleles can be 162 identified to introgress into modern cultivars. In essence, the knowledge of allelic diversity in gene 163 bank materials provides historical insights into resistance gene deployment and evolution and 164 might improve our understanding of host-pathogen interactions.

Domestication, early landrace selection and modern breeding have significantly reduced the genetic diversity in today's elite wheat gene pool (Tanksley and McCouch 1997; Reif et al. 2005; Wang et al. 2014). This exposes the vulnerability of modern wheat varieties to emerging diseases and sudden epidemics as they carry few resistance genes with low durability (e.g. wheat blast and stem rust; Islam et al. 2016; Singh et al. 2015). In contrast, wheat gene banks conserve hundreds of thousands of accessions (including wild relatives and landraces), which represent a reservoir of 172 genetic diversity for various traits (Milner et al. 2019; Hajjar and Hodgkin 2007). The value of 173 wheat landraces in harboring novel resistance genes or alleles has been demonstrated for different 174 diseases (Cavanagh et al. 2013; Mengistu et al. 2016). However, efforts to utilize wheat landraces 175 for finding novel sources of STB resistance are largely lacking. The Swiss gene bank conserves 176 more than $\sim 7,500$ wheat accession. Despite STB being a major disease in Central Europe, it is 
177 unclear whether Swiss wheat landraces carry any novel STB resistance genes or alleles that can be

178 utilized in STB resistance breeding.

Most of the reported Stb genes have been identified using bi-parental QTL mapping, which provided valuable information for resistance gene pyramiding. However, the allelic variation of identified genes is restricted to the two parental genotypes involved in generating the progenies. Genome-wide association mapping (GWAS) provides a wider opportunity to study the allelic 184 diversity of genes as it can be done on natural populations or germplasm collections (Hall, Tegström, and Ingvarsson 2010). GWAS identifies the genomic position of a gene more precisely due to historical recombination events accumulated over generations in natural populations $(\mathrm{Yu}$ and Buckler 2006). Relatively few GWAS studies have been done on European wheat cultivars to find novel sources of STB resistance (Kollers et al. 2013; Miedaner et al. 2013; Vagndorf et al. 2017; Yates et al. 2019). In this study, we characterized a panel of 188 historic wheat landraces from the Swiss Gene Bank for resistance to STB. We performed GWAS to identify novel genetic variants based on the amount of leaf area covered by necrotic lesions and the density of pycnidia within lesions using four Swiss Z. tritici isolates. We characterized the allelic diversity of the Stb6 gene, which may provide valuable information to wheat breeders while using these landraces for

194 STB resistance breeding.

\section{Materials and Methods}

Plant and fungal material

A collection of 188 bread wheat (Triticum aestivum ssp. aestivum) and spelt (Triticum aestivum spp. spelta) accessions (Supplementary Table S1) was selected for this study from a genetically characterized panel of 795 wheat landraces (Müller et al. 2018). These landraces were obtained

203 from the Swiss National Gene Bank (www.bdn.ch) and represent the Swiss wheat breeding history 204 from the early 1900s to date. The panel contains a mixture of local varieties, modern varieties, and 205 breeding lines. Two control wheat genotypes, Chinese Spring (a landrace carrying isolate-specific 206 resistance) and Drifter (a highly susceptible modern cultivar), were used in the disease 207 phenotyping experiment. We used four isolates of $Z$. tritici, namely 1E4, 1A5, 3D1, and 3D7 for 
208 the infection assay. These isolates were collected from two nearby Swiss wheat fields in 1999 209 (Zhan et al. 2005) and have been fully sequenced (Croll, Zala, and McDonald 2013; Lendenmann 210 et al. 2014). Previous studies identified the fungal avirulence genes AvrStb6 (Zhong et al. 2017) 211 and $A v r 3 D 1$ (Meile et al. 2018) in isolates 1E4 and 3D1, respectively.

\section{Preparation of fungal inoculum}

214

215 The isolates were retrieved from long-term glycerol storage by following standard laboratory 216 protocols. Simply, $40 \mu \mathrm{l}$ of concentrated spore suspension from each isolate were added into 100$217 \mathrm{ml}$ Erlenmeyer flasks containing $50 \mathrm{ml}$ of yeast sucrose broth (YSB, $10 \mathrm{~g} / \mathrm{L}$ sucrose, $10 \mathrm{~g} / \mathrm{L}$ yeast 218 extract amended with $50 \mu \mathrm{g} / \mathrm{ml}$ kanamycin sulfate to control other microbial growth). Blastospore 219 production was facilitated by keeping the flasks at $18^{\circ} \mathrm{C}$ on a continuous shaker at $120 \mathrm{rpm}$. After 220 five days of growth, blastospores were collected by filtering the liquid media through two layers 221 of sterile cheesecloth. Subsequently, blastospores were pelleted for each isolate by centrifugation $222\left(1,575 \mathrm{~g}, 15 \mathrm{~min}, 4^{\circ} \mathrm{C}\right)$, traces of residual growth media were removed by washing with sterile 223 water and spores were resuspended in sterile water. The spores were counted and adjusted to a 224 final concentration of $5 \times 10^{6}$ spores $/ \mathrm{ml}$ using KOVA counting slides (Hycor Biomedical, Inc., 225 Garden Grove, CA, USA).

226

Disease phenotyping and data collection

228

Two grains of each landrace were sown in an individual Jiffy square pot filled with peat substrate Jiffy GO PP7 (Jiffy Products International, Moerdijk, the Netherlands). Each pot is a part of a Jiffy pot strip and eight strips of Jiffy pots were arranged in a tray to accommodate 96 wheat landraces. Grains were subjected to a cold pre-treatment for five days to break the dormancy and synchronize germination. After the pre-treatment, trays were kept in a greenhouse chamber at $22^{\circ} \mathrm{C}$ (day) and $23418^{\circ} \mathrm{C}$ (night) with $70 \%$ relative humidity $(\mathrm{RH})$ and $16-\mathrm{hr}$ photoperiod. Inoculation with the fungal spores was performed on 14-day-old seedlings with a fully expanded second leaf. The final volume of each spore suspension used for inoculation was adjusted to $75 \mathrm{ml}$ by adding sterile water 237 supplemented with $0.1 \%$ of the TWEEN 20 surfactant. The third leaf and subsequent leaves were 
239 uniform distribution of spores and better light penetration into the inoculated leaf. We used an

240 airbrush spray gun (1A Profi Handels $\mathrm{GmbH}$, Wiesbaden, Germany) to inoculate each tray 241 containing 96 wheat genotypes uniformly until run-off. The spraying was done in a confined area

242 for each isolate separately to minimize any chance of cross-contamination. The trays were covered 243 with plastic wrapped around a metal frame after inoculation to provide $100 \% \mathrm{RH}$ and transferred 244 back into the greenhouse chamber. Three independent biological replicates were obtained by 245 repeating the experiments three times over three consecutive weeks. Spraying of all four isolates 246 was performed on a single day.

247 Plastic covers were removed three days post-inoculation (dpi) and plants were kept at the same 248 environmental conditions as before. The second leaf of each infected landrace for each isolate was 249 harvested at 21 dpi. Each second leaf was excised and mounted on A4 paper for scanning as 250 described previously (Karisto et al. 2018). Each A4 sheet containing eight inoculated leaves was 251 scanned using a flatbed scanner (CanoScan LiDE 220) for automated image analysis (AIA; Karisto 252 et al. 2018). The AIA provided quantitative data on the percent of leaf area covered by lesions 253 (PLACL) and pycnidia density per $\mathrm{cm}^{2}$ of the lesions on each leaf. Importantly, AIA facilitates 254 separation of resistance that affects pathogen damage from the resistance that affects pycnidia 255 production (a quantitative measure of pathogen reproduction).

256 Genome-wide association analysis

258 For each isolate, we implemented a linear model using the $\operatorname{lm}()$ function from the package "stats" 259 in R-studio (R Core Team, 2019) to obtain the least square (LS) means for PLACL and pycnidia 260 density for each landrace. Prior to linear modeling, raw data were log-transformed to fulfill the 261 normality assumptions. We reported un-transformed data in figures and texts for clarity. We used 262 the un-transformed data to perform a global Kruskal-Wallis test (Sokal and Rohlf 2012) using the 263 kruskal.test function in R-studio to observe the difference among the four isolates for both traits. 264 We performed genome-wide association mapping (GWAS) on PLACL and pycnidia density for 265 each isolate individually using the log-transformed LS-means and 9,284 bi-allelic single 266 nucleotide polymorphisms (SNP) at 5\% minor allele frequency obtained from Müller et al. (2018). 267 The Illumina Infinium 15K wheat SNP array (TraitGenetics GmbH, Gatersleben, Germany) 268 containing 13,006 SNPs was used to genotype the landraces and obtain the final SNP dataset 
269 (Müller et al. 2018). All the GWAS analyses were performed using the R package GAPIT v.3.0 270 (Tang et al. 2016). A mixed linear model (MLM) was selected for the GWAS as it improves the 271 control of false positives by including fixed and random effects (Yu et al. 2006). A kinship matrix 272 was estimated by following VanRaden's method (VanRaden 2008) implemented in GAPIT. We 273 also conducted principal component analysis (PCA) and added it to the GWAS model as a fixed 274 effect. Both PCA and kinship matrix are useful in controlling false positive signals due to 275 population structure and cryptic genetic relatedness in GWAS. However, the inclusion of principal 276 components did not improve the GWAS model as suggested by the Bayesian information criterion 277 (BIC; (Schwarz 1978), hence these were excluded. Thus, the MLM model with a kinship matrix 278 as a random effect was selected as the most appropriate for our GWAS analysis. Considering the 279 relatively small sample size $(n=188)$, we used an MLM instead of a compressed MLM, which 280 groups individuals according to phenotypes following the implementation in GAPIT (Zhang et al. 281 2010). The following mixed linear model was used: $y=X b+Z u+e$, where $y$ is the vector of 282 phenotypes, $X$ and $Z$ are the known design matrices, $b$ is the unknown vector of fixed effects 283 (SNPs), $u$ is the vector of random effects (based on the kinship matrix) and $e$ is the vector of 284 residual effects. We used the stringent Bonferroni threshold $\left(\alpha=0.05 ;-\log _{10}(P)=5.27\right)$ to detect significant marker-trait associations. Manhattan plots and qq-plots were generated by using the $\mathrm{R}$ package qqman (Turner, 2014). The variation in the phenotypic traits explained by significant SNPs was determined using a linear model with the $\operatorname{lm}()$ function implemented in the "stats" package in R. Phenotypic trait values were used as response variables and the SNPs as fixed 289 effects.

Molecular screening and sequencing of the Stb6 alleles

293 Two-week-old second leaves from 188 landraces and Chinese Spring (control) were lyophilized, 294 grounded into powder and genomic DNA was extracted using the DNeasy Plant Mini DNA 295 extraction kit (Qiagen GmbH, Hilden, Germany) following the manufacturer's protocol. The Stb6 296 gene contains four exons in total (Saintenac et al. 2018) and can be amplified with two separate 297 polymerase chain reactions (PCR). We used the primers $8311 \mathrm{~F} 19$ (forward primer, 298 CGCGGTTCCAGTCACATCAC) and 8311F3 (reverse, CCGTTTAGCTCGTGTTGTGC) to 299 amplify the exon 1 with a PCR product length of $\sim 1.6$ kilobase pair $(\mathrm{kb})$. The remaining exons 2 - 
4 were amplified using the primers 8311F16 (forward, GCGACATGGTAGCTCAATCAAA) and 8311R16 (reverse, TTCCTTCCATGGTCGGTAACTT) with a PCR product length of $\sim 2.0 \mathrm{~kb}$. The primer sequences were obtained from Saintenac et al. (2018). PCR amplification of the first exon was performed in a total volume of $20 \mu \mathrm{L}$. The PCR mix contained $1 \mu \mathrm{L}(10 \mu \mathrm{M})$ of each forward and reverse primer, $2.5 \mu \mathrm{L}(20 \mathrm{ng} / \mu \mathrm{L}) \mathrm{DNA}, 5.5 \mu \mathrm{L}$ DNase/RNase free water and $10 \mu \mathrm{L}$ of AmpliTaq Gold 360 Master Mix (Applied Biosystems). The PCR cycle conditions were: 10 min of initial denaturation at $95^{\circ} \mathrm{C}$ followed by 40 cycles of $95^{\circ} \mathrm{C}$ for $30 \mathrm{~s}$, annealing at $63^{\circ} \mathrm{C}$ for $30 \mathrm{~s}, 72^{\circ} \mathrm{C}$ for $45 \mathrm{~s}$ and final extension at $72^{\circ} \mathrm{C}$ for $5 \mathrm{~min}$. PCR amplification of the remaining exons was performed with the Phusion ${ }^{\circledR}$ High-Fidelity PCR Master Mix with HF Buffer (Thermo Scientific) keeping other parameters unchanged. The PCR cycle parameters were: 1 min of initial denaturation at $98^{\circ} \mathrm{C}$ followed by 40 cycles of $98^{\circ} \mathrm{C}$ for $10 \mathrm{~s}$, annealing at $69^{\circ} \mathrm{C}$ for $30 \mathrm{~s}, 72^{\circ} \mathrm{C}$ for 1 min, and final extension at $72^{\circ} \mathrm{C}$ for 5 min. PCR products were visualized on $1 \%$ agarose gels. PCR reactions were purified to remove unincorporated nucleotides and primers using MachereyNagel $^{\mathrm{TM}}$ NucleoSpin ${ }^{\mathrm{TM}}$ Gel and PCR Clean-up Kit (Macherey-Nagel, Oensingen, Switzerland). The purified PCR reactions were sent to GATC Biotech SARL (Konstanz, Germany) for Sanger sequencing with the above-mentioned primers.

317 Forward and reverse Sanger sequences of 178 landraces were trimmed to remove low-quality 318 sequence, assembled, aligned to produce nucleotide sequence alignment and translated into protein 319 sequences using the genomic analysis software Geneious, v 9.1.8 (Biomatters, Auckland, New 320 Zealand) and the implemented MUSCLE algorithm. Multiple sequence alignment of landrace 321 sequences along with previously identified Stb6 alleles (Saintenac et al. 2018) was performed to 322 identify sequence polymorphisms and the existence of any novel alleles. Phylogenetic analysis 323 was performed using the DNA sequences from the landraces together with previously reported 324 Stb6 alleles and the homeologs of the Stb6 gene to analyze their genetic relatedness. We performed 325 a BLAST search of the Stb6 resistance allele against the wheat reference genome in Chinese Spring 326 (RefSeq v1.0) provided by the International Wheat Genome Sequencing Consortium (IWGSC; 327 Appels et al. 2018) and used the homoeologous genes on chromosome 3B and 3D in the 328 phylogenetic tree. A distantly related WAK kinase gene from Aegilops tauschii 329 (XM_020327419.1) was used as an outgroup. The rooted phylogenetic tree was constructed using 330 the 'Neighbor-joining' method and 'Jukes-Cantor' for nucleotide distance measure and a bootstrap 
performed with 1,000 replications in the Geneious software. In cases of high dissimilarity (i.e. high degree of polymorphism in the conserved protein kinase region) between the reported Stb6 alleles and landraces alleles, we performed an additional PCR with the reverse complements of the reverse primer of Exon 1 and the forward primer of the remaining exons to join the two ends. The amplified PCR product was $\sim 2.1 \mathrm{~kb}$ long and PCR conditions were kept the same as with the Phusion ${ }^{\circledR}$ High-Fidelity PCR Master Mix with HF Buffer (Thermo Scientific). We used the Stb6 resistance allele as a control group and visualized the amplifications on $1 \%$ agarose gels.

\section{Results and Discussion}

\section{Phenotypic variation for resistance to STB among Swiss wheat landraces}

We obtained quantitative data on the amount of leaf necrosis and pycnidia density from the interactions between 188 wheat landraces and four $Z$. tritici strains using AIA to characterize the resistance response to STB. The landraces showed a considerable degree of phenotypic variability for both traits for the four isolates (Fig. 1a, b, Supplementary Table S1). There were significant differences $\left(P<2.2 \mathrm{e}^{-16}\right)$ among the four isolates for PLACL and pycnidia density (Fig. 2a, b). Using the non-transformed data, PLACL and pycnidia density with the isolate 1A5 ranged from $2 \%$ to $99 \%$ and 0 to 30 with means of $66 \%$ and 8.3 , respectively. Similar ranges of PLACL and pycnidia density were observed with the other three isolates. The majority of the landraces showed high resistance to the isolate $1 \mathrm{E} 4$ with a mean PLACL of $28 \%$ and a pycnidia density of 17 . Around $48 \%$ of the landraces showed very high resistance (PLACL $<10 \%$ ) to isolate 1E4, suggesting the presence of a major gene following a gene-for-gene relationship with the corresponding Avr (possibly AvrStb6). In contrast, the majority of the landraces were moderately to highly susceptible to the isolates 3D1 (mean PLACL of 63 and pycnidia density of 14) and 3D7 (mean PLACL of 74 and pycnidia density of 38). In terms of infectivity, the isolate 3D7 appeared the most damaging overall to Swiss wheat landraces. However, a greater proportion of the landraces with high PLACL were able to suppress pathogen reproduction as indicated by the overall low pycnidia density and its low correlation with PLACL in 1A5 $(r=0.2, P=0.005)$ and 3D1 $\left(r=0.38, P=1.1 \mathrm{e}^{-07}\right)$ compared to 1E4 and 3D7 (Supplementary Fig. S1). This may indicate the different genetic resistance mechanism for PLACL and pycnidia density. A field-based study comprising 335 elite wheat cultivars indicated that host resistance affecting leaf necrosis and host resistance affecting 
pathogen reproduction were under different genetic control (Karisto et al. 2018; Yates et al. 2019).

364 Even after successful colonization of the leaf, nutrient availability and genetic resistance can largely suppress pathogen reproduction. Such components of host resistance can be beneficial in reducing in-field pathogen inoculum load that causes epidemics. The higher phenotypic variation for both traits in the three isolates except 1E4 suggests that host resistance is governed by a complex genetic architecture. Additionally, we identified two landraces, 1011 (PLACL $<9 \%$ and pycnidia density $=0$ ) and 1030 (PLACL $<6 \%$ and pycnidia density $=0$ ) that were highly resistant for both traits to all four Z. tritici isolates (Supplementary Table S1). These landraces are promising candidates for identifying novel STB resistance genes through bi-parental QTL 372 mapping.

\section{Genome wide association study identifies $S t b 6$ as the major STB resistance locus}

We conducted a mixed linear model GWAS on PLACL and pycnidia density for each of the four isolates separately. There was considerable genetic variation among the landraces as depicted by the kinship matrix (Supplementary Fig. S2). The spelt group clustered together, indicating high genetic similarity. We included the kinship matrix as a random effect in the GWAS model to control $p$-value inflation caused by such genetic clustering and cryptic relatedness. We identified a significant SNP (Excalibur_c34649556) over the stringent Bonferroni threshold ( $p$-value $<$ $7.80 \times 10^{-09}$, minor allele frequency $=0.12$ ) on wheat chromosome $3 \mathrm{~A}$ at $26,461,994 \mathrm{bp}$ associated with PLACL and pycnidia density in the isolate 1E4 (Fig. 3a, b). Using the genome browser of IWGSC RefSeq v1.0, we found that the SNP is located $\sim 255 \mathrm{~kb}$ upstream of the major STB resistance gene Stb6. Linkage disequilibrium (LD) in wheat is large in comparison to other cereals due to its self-pollinating nature (Cavanagh et al. 2013; Wang et al. 2014; Pang et al. 2020). Pang et al. (2020) showed that the average genome-wide LD block size in wheat is around 4.2 Mb. In another study, LD decayed at more than $7 \mathrm{Mb}$ in different populations including landraces and modern cultivars (Liu et al. 2019). In the current landrace population, LD decayed after $1.94 \mathrm{Mb}$ in bread wheat and after $6.34 \mathrm{Mb}$ in spelt wheat landraces (Müller et al. 2018). Hence, we consider it likely that the resistance to 1E4 was controlled by the Stb6 gene. However, the significant SNP explained only $18 \%$ and $8 \%$ of the phenotypic variation for PLACL and pycnidia density, 
response, which GWAS could not detect due to the low SNP density. A recent study identified a

395 QTL in close proximity to the Stb6 gene that provided partial resistance to STB in a durum wheat panel (Ballini et al. 2020). GWAS analysis for both traits in the other three isolates did not detect any significantly associated SNP. This suggests that host resistance towards these isolates was controlled by many small effect loci (i.e. quantitative resistance). Quantitative host resistance to STB has been observed previously in field-based studies (Kidane et al. 2017; Muqaddasi et al. 2018; Yates et al. 2019). The majority of the landraces carrying the " $\mathrm{T}$ " allele of the significant SNP were highly resistant for both traits (Fig. 4a, b) suggesting that it is the favorable allele. However, several landraces carrying this allele were susceptible to 1E4 for both traits, raising the possibility that these landraces contain an alternate susceptible allele or that there was recombination in the $255 \mathrm{~kb}$ region separating the SNP and Stb6.

\section{Widespread prevalence of Stb6 resistance allele among Swiss wheat landraces}

To validate the presence of the Stb6 gene, we amplified the full-length coding sequence using gene-specific primers from Saintenac et al. (2018) and Sanger sequenced the two PCR products in

410178 landraces (Supplementary Fig. S3). Ten landraces failed to amplify a PCR product, perhaps 411 due to the absence of a Stb6 allele. We identified 118 landraces (66\%) that carried the functional 412 reference resistance Stb6-1 allele (GeneBank accession number KY485190.1) and 24 landraces 413 (13\%) that carried the reference susceptible Stb6-3 allele first described in the susceptible wheat cultivar Courtot (KY485192.1). The remaining 36 landraces carried seven novel Stb6 alleles (Stb618 to Stb6-24) that were not previously reported by Saintenac et al. (2018). We categorized the landraces into several groups based on single nucleotide polymorphisms (SNP) compared to the

417 reference Stb6-1 allele (Fig. 5). The two alleles Stb6-21 and Stb6-24 were identified in single 418 landraces whereas the remaining unique alleles were identified in several landraces. We created a 419 neighbor-joining tree with all the published Stb6 alleles, including alleles (Stb6-18 to Stb6-24) 420 from this study and two Stb6 homoeologous sequences, to evaluate the genetic relatedness among 421 them (Fig. 6). The Stb6-18 and Stb6-19 alleles were closely related to the homoeologous sequences 422 on chromosome 3B and 3D, respectively and clustered independently from all other Stb6 alleles.

423 These two alleles were characterized by an unusually high number of SNPs in the 3' region 424 encoding the protein kinase domain, while the 5' region of the gene encoding the extracellular 
425 domain showed a high degree of sequence similarity to Stb6-1 (Fig. 5). Because the Stb6 alleles

426 were amplified by two independent PCR reactions, we tested if the two amplicons of Stb6-18 and

427 Stb6-19 were from the same genomic region. To do so, we developed a PCR probe that bridges

428 the two independent PCR amplicons. While this probe amplified in Stb6-1 containing landraces,

429 we obtained no amplification product in the Stb6-18 and Stb6-19 containing landraces

430 (Supplementary Fig. S4). This suggests that these two alleles are not real. The most likely

431 explanation is that the Stb6 gene in these landraces is truncated and only contains the 5' region.

432 The 3' region might have been amplified from the homoeologous chromosomes. The alleles Stb6-

43320 and Stb6-24 contained seven and ten synonymous SNPs compared to the reference Stb6-1 allele,

434 respectively and their predicted protein sequence showed 100\% similarity to the deduced protein

435 sequence of the previously reported Stb6-7 (KY485196.1) allele. The alleles Stb6-21, Stb6-22 and

436 Stb6-23 carried few synonymous SNPs compared to the reference Stb6-1 allele and showed

437 comparable susceptibility to the susceptible allele Stb6-3 (KY485192.1) (Fig. 7). Our analysis of

438 gene bank material did not find any novel resistance alleles, confirming previous results that there

439 is only one functional Stb6 resistant allele (Stb6-1). Five landraces carrying the resistance Stb6-1

440 allele showed moderate to high susceptibility (PLACL > 40\%) towards 1E4 and several landraces

441 produced moderate numbers of pycnidia within lesions (Fig. 7). This can result from the presence

442 of a suppressor gene that is inhibiting the resistance response of Stb6. Suppressor genes often

443 interact with a specific resistance gene and promote susceptibility (Kema et al. 1995; Ren et al.

444 1997). The presence of suppressor genes hindering the resistance gene action have been reported

445 for STB (Arraiano et al. 2007) and different rust diseases in wheat (Zeller and Hsam, 1996; Nelson

446 et al. 1997; Wu et al. 2015). Further experiments are required to validate the presence of a

447 suppressor gene interacting with the resistance gene in these landraces.

449 The high frequency of Stb6 among these $\sim 100$ year-old-landraces is intriguing. Previous studies 450 demonstrated that Stb6 is a very old gene and widely present in worldwide wheat cultivars 451 (Chartrain, Brading, and Brown 2005). During the initial phases of Swiss wheat breeding programs 452 in the early 1900s, wheat germplasms were frequently exchanged between Switzerland and its 453 neighboring countries (Dr. Fabio Mascher, Agroscope, personal communication). This might have 454 contributed to the widespread distribution of Stb6, although its origin among the Swiss landraces 455 still remains unknown. Importantly, the majority of the landraces (including 28 spelt wheat out of 
45631 tested) carried the resistance Stb6 allele. In contrast, such a high frequency of the resistance

457 allele of Lr34 (leaf rust resistance gene) was not observed in landrace populations worldwide 458 (Krattinger et al 2009; Kolmer et al. 2008). Although STB became an important disease in Europe 459 and started to draw attention of wheat breeders in the 1970s, it already inflicted heavy to moderate 460 yield loss in Switzerland before 1950 (Zogg, Horber and Salzmann, 1950). Given the conspicuous 461 nature of STB symptoms and the ability to cause significant yield loss, we can assume that farmers 462 in the past could easily identify the disease and observe the resistance response of different 463 landraces. Since Stb6 provides some field resistance (Chartrain, Brading, and Brown 2005), we 464 can speculate that the more resistant landraces carrying Stb6 were continuously selected and 465 exchanged among Swiss farmers, and were incorporated into breeding programs that resulted in 466 the high frequency of the resistance allele. Moreover, the widespread distribution of the resistance 467 Stb6 allele may explain the lack of improvement for STB resistance in earlier times. As the 468 knowledge of the particular gene was lacking, breeders might have been crossing wheat genotypes 469 both carrying the same Stb6 allele and failed to improve STB resistance by transgressive 470 segregation.

472 Although this study did not identify a new resistance-conferring Stb6 allele, we demonstrate the 473 value of 'digital' gene bank information for gene discovery in historic wheat collections. The 474 knowledge of allelic distribution from this study will help breeders to make decisions on 475 integrating these materials into breeding programs to improve STB resistance. For example, the 476 two highly resistant landraces identified in this study can be incorporated into QTL mapping 477 studies to elucidate their mechanism of resistance to all four isolates. Also, crossing between 478 cultivars containing the Stb6-1 resistance allele and highly resistant landraces lacking the Stb6-1 479 allele might result in transgressive segregation and improve STB resistance. Additionally, such 480 landraces can be used in developing near-isogenic lines in the genetic background of modern 481 cultivars to precisely determine the phenotypic effect of resistance genes and perform map-based 482 cloning. As our disease phenotyping was limited to four Swiss isolates, increasing the diversity in 483 the isolates used for inoculation or evaluating these landraces under natural field conditions may 484 help to detect other resistance loci. 
489 This work was funded by the Swiss Federal Office for Agriculture (BLW) in the framework of 490 NAP-PGREL (National Plan of Action for the Conservation and Sustainable Utilization of Plant 491 Genetic Resources) Project Nr. 627000640. We are thankful to Dr. Fabio Mascher, Dr. Dario 492 Fossati, and Beate Schierscher for providing valuable discussions on the history of these landraces 493 in STB resistance breeding. We thank Dr. Danilo Dos Santos Pereira, Alessio Bernasconi, Dr. 494 Petteri Karisto, Maria Zwyssig and Susanne Dora for help in collecting phenotypic data. 495

\section{Conflict of interest}

497

498 The authors declare no conflict of interest.

499

500

Author contributions

501

$502 \mathrm{AD}, \mathrm{DC}, \mathrm{BAM}$ and SK conceived the idea of this study. AD conducted the experiment, collected 503 phenotypic data, performed data analysis and wrote the first manuscript draft. BAM provided 504 funding. All co-authors edited and approved the final version of the manuscript.

505

506 Data availability

507 Raw phenotypic data can be provided upon request.

508

509

510

511

512

513

514 


\section{References}

516 Arraiano LS, Kirby J and Brown JKM (2007) Cytogenetic analysis of the susceptibility of the 517 wheat line Hobbit sib (Dwarf A) to Septoria tritici blotch. Theoretical and Applied Genetics $518 \quad 116(1): 113-122$.

519 Ballini E, Tavaud M, Ducasse A, Sanchez D, Paux E, Kitt J, Charmet G, Audigeos, D, Roumet, 520 P, David, J, Morel, JB (2020) Genome wide association mapping for resistance to multiple 521 fungal pathogens in a panel issued from a broad composite cross-population of tetraploid wheat

522 Triticum turgidum. Euphytica 216:1-17.

523 Bhullar NK, Street K, Mackay M, Yahiaoui N, Keller B (2009) Unlocking Wheat Genetic 524 Resources for the Molecular Identification of Previously Undescribed Functional Alleles at the 525 Pm3 Resistance Locus. Proceedings of the National Academy of Sciences of the United States of 526 America 106(23): 9519-24.

527 Bhullar NK, Zhang Z, Wicker T, Keller B (2010) Wheat Gene Bank Accessions as a Source of 528 New Alleles of the Powdery Mildew Resistance Gene Pm3: A Large Scale Allele Mining 529 Project. BMC Plant Biology 10(1): 1-13.

530 Brown JKM, Chartrain L, Zuber PL, Saintenac C (2015) Genetics of Resistance to Zymoseptoria

532 Cavanagh CR, Chao S, Wang S, Huang BE, Stephen S, Kiani S, Forrest K et al (2013) Genome533 Wide Comparative Diversity Uncovers Multiple Targets of Selection for Improvement in 534 Hexaploid Wheat Landraces and Cultivars. Proceedings of the National Academy of Sciences of 535 the United States of America 110(20): 8057-62.

536 Cowger C, Hoffer ME, Mundt CC 2000. Specific Adaptation by Mycosphaerella Graminicola to 537 a Resistant Wheat Cultivar. Plant Pathology 49(4): 445-51.

538 Croll D, Zala M, McDonald BA (2013) Breakage-Fusion-Bridge Cycles and Large Insertions 539 Contribute to the Rapid Evolution of Accessory Chromosomes in a Fungal Pathogen. PLoS 540 Genetics 9(6): e1003567.

541 Estep LF, Torriani SFF, Zala M, Anderson NP, Flowers MD, McDonald BA, Mundt CC, 542 Brunner PC (2015) Emergence and Early Evolution of Fungicide Resistance in North American 543 Populations of Zymoseptoria tritici. Plant Pathology 64(4): 961-71.

544 Fones H, Gurr S (2015) The Impact of Septoria Tritici Blotch Disease on Wheat: An EU 545 Perspective. Fungal Genetics and Biology 79: 3-7.

546 Hajjar R, Hodgkin T (2007) The Use of Wild Relatives in Crop Improvement: A Survey of 547 Developments over the Last 20 Years. Euphytica 156(1): 1-13.

548 Hall D, Tegström C, Ingvarsson PK (2010) Using Association Mapping to Dissect the Genetic 549 Basis of Complex Traits in Plants. Briefings in Functional Genomics 9(2): 157-65. 
550 Hayes LE, Sackett KE, Anderson NP, Flowers MD, Mundt CC (2016) Evidence of Selection for 551 Fungicide Resistance in Zymoseptoria tritici Populations on Wheat in Western Oregon. Plant 552 Disease 100(2): 483-89.

553 Appels R, Eversole K, Stein N, Feuillet C, Keller B, Rogers J, Pozniak CJ et al (2018) Shifting 554 the limits in wheat research and breeding using a fully annotated reference genome. Science $55536(6403)$

556 Islam MT, Croll D, Gladieux P, Soanes DM, Persoons A, Bhattacharjee P, Hossain MS et al 557 (2016) Emergence of Wheat Blast in Bangladesh Was Caused by a South American Lineage of 558 Magnaporthe oryzae. BMC Biology 14(1): 84.

559 Jacob F, Vernaldi S, Maekawa T (2013) Evolution and Conservation of Plant NLR Functions. 560 Frontiers in Immunology 4:297.

561 Jørgensen LN, Hovmøller MS, Hansen JG, Lassen P, Clark B et al (2014) IPM Strategies and 562 Their Dilemmas Including an Introduction to www.eurowheat. org. Journal of Integrative 563 Agriculture 13(2):265-281.

564 Karisto P, Hund A, Yu K, Anderegg J, Walter A, Mascher F, McDonald BA, Mikaberidze A 565 (2018) Ranking Quantitative Resistance to Septoria Tritici Blotch in Elite Wheat Cultivars Using 566 Automated Image Analysis. Phytopathology 108(5): 568-81.

567 Kema GHJ, Lange W, Silfhout CHV (1995) Differential suppression of stripe rust resistance in 568 synthetic wheat hexaploids derived from Triticum turgidum subsp. dicoccoides and Aegilops 569 squarrosa. Phytopathology (USA).

570 Kollers S, Rodemann B, Ling J, Korzun V, Ebmeyer E, Argillier O, Hinze M et al (2013) 571 Genetic Architecture of Resistance to Septoria Tritici Blotch (Mycosphaerella graminicola) in 572 European Winter Wheat. Molecular Breeding 33(2):411-423.

573 Lendenmann MH, Croll D, Stewart EL, McDonald BA (2014) Quantitative Trait Locus Mapping 574 of Melanization in the Plant Pathogenic Fungus Zymoseptoria tritici. G3: Genes, Genomes, 575 Genetics 4(12): 2519-33.

576 Liu Y, Wang H, Jiang Z, Wang W, Xu R, Wang Q, Zhang Z, Li A, Liang Y, Ou S, Liu X (2021) 577 Genomic basis of geographical adaptation to soil nitrogen in rice. Nature: 1-6.

578 McDonald BA, Mundt CC (2016) How Knowledge of Pathogen Population Biology Informs 579 Management of Septoria Tritici Blotch. Phytopathology 106(9): 948-55.

580 Meile L, Croll D, Brunner PC, Plissonneau C, Hartmann FE, McDonald BA, Vallet AS (2018) A 581 Fungal Avirulence Factor Encoded in a Highly Plastic Genomic Region Triggers Partial

582 Resistance to Septoria Tritici Blotch. The New Phytologist 219(3): 1048-61.

583 Mengistu DK, Kidane YG, Catellani M, Frascaroli E, Fadda C, Pè ME, Acqua MD (2016) High584 Density Molecular Characterization and Association Mapping in Ethiopian Durum Wheat 585 Landraces Reveals High Diversity and Potential for Wheat Breeding. Plant Biotechnology 
Journal 14(9): 1800-1812.

587 Miedaner T, Zhao Y, Gowda M, Longin CFH, Korzun V, Ebmeyer E, Kazman E, Reif JC (2013)

588 Genetic Architecture of Resistance to Septoria Tritici Blotch in European Wheat. BMC

589 Genomics 14(1): 1-8.

590 Milner SG, Jost M, Taketa S, Mazón E, Himmelbach A, Oppermann M, Weise S et al (2019)

591 Genebank Genomics Highlights the Diversity of a Global Barley Collection. Nature Genetics

592 51(2): 319-26.

593 Müller T, Viret BS, Fossati D, Brabant C, Schori A, Keller B, Krattinger SG (2018) Unlocking 594 the Diversity of Genebanks: Whole-Genome Marker Analysis of Swiss Bread Wheat and Spelt.

595 TAG. Theoretical and Applied Genetics 131(2): 407-16.

596 Muqaddasi QH, Zhao Y, Rodemann B, Plieske J, Ganal MW, Röder MS, (2019) Genome-wide 597 Association Mapping and Prediction of Adult Stage Septoria tritici Blotch Infection in European 598 Winter Wheat via High-Density Marker Arrays. The Plant Genome 12(1):1-13.

599 Nelson JC, Singh RP, Autrique JE, Sorrells ME, (1997) Mapping genes conferring and 600 suppressing leaf rust resistance in wheat. Crop science 37(6):1928-1935.

601 Pang Y, Liu C, Wang D, Amand PS, Bernardo A, Li W, He F et al (2020) High-Resolution 602 Genome-Wide Association Study Identifies Genomic Regions and Candidate Genes for 603 Important Agronomic Traits in Wheat. Molecular Plant 13(9): 1311-27.

604 Ponomarenko A, Goodwin SB, Kema GHJ (2011) Septoria Tritici Blotch (STB) of Wheat.

605 Ray DK, Mueller ND, West PC, Foley JA (2013) Yield Trends Are Insufficient to Double 606 Global Crop Production by 2050. PloS One 8(6): e66428.

607 Reif JC, Zhang P, Dreisigacker S, Warburton ML, Ginkel MV, Hoisington D, Bohn M, 608 Melchinger AE (2005) Wheat Genetic Diversity Trends during Domestication and Breeding. 609 TAG. Theoretical and Applied Genetics (5): 859-64.

610 Ren SX, McIntosh RA, Lu ZJ (1997) Genetic suppression of the cereal rye-derived gene Pm8 in 611 wheat. Euphytica 93(3):353-360.

612 Saintenac C, Lee WS, Cambon F, Rudd JJ, King RC, Marande W, Powers SJ et al (2018) Wheat 613 Receptor-Kinase-like Protein Stb6 Controls Gene-for-Gene Resistance to Fungal Pathogen 614 Zymoseptoria tritici. Nature Genetics 50(3): 368-74.

615 Savary S, Willocquet L, Pethybridge SJ, Esker P, McRoberts N, Nelson A (2019) The Global 616 Burden of Pathogens and Pests on Major Food Crops. Nature Ecology \& Evolution 3(3):430617439.

618 Schwarz G (1978) Estimating the Dimension of a Model. Annals of Statistics 6(2): 461-64.

619 Singh RP, Hodson DP, Jin Y, Lagudah ES, Ayliffe MA, Bhavani S, Rouse MN et al (2015) 
620 Emergence and Spread of New Races of Wheat Stem Rust Fungus: Continued Threat to Food 621 Security and Prospects of Genetic Control. Phytopathology 105(7): 872-84.

622 Sokal RR, Rohlf FJ (2012) Biometry, 4th Edn New York. NY: WH Freeman and Company.

623 Tang Y, Liu X, Wang J, Li M, Wang Q, Tian F, Su Z et al (2016) GAPIT Version 2: An

624 Enhanced Integrated Tool for Genomic Association and Prediction. The Plant Genome 9(2).

625 Tanksley SD, McCouch SR (1997) Seed Banks and Molecular Maps: Unlocking Genetic 626 Potential from the Wild. Science 277(5329): 1063-66.

627 Turner, SD (2014) qqman: an R package for visualizing GWAS results using QQ and manhattan 628 plots. Biorxiv 005165.

629 Vagndorf N, Nielsen NH, Edriss V, Andersen JR, Orabi J, Jørgensen LN, Jahoor A (2017)

630 Genomewide Association Study Reveals Novel Quantitative Trait Loci Associated with

631 Resistance towards Septoria Tritici Blotch in North European Winter Wheat. Plant Breeding 136 632 (4): 474-82.

633 VanRaden PM (2008) Efficient Methods to Compute Genomic Predictions. Journal of Dairy 634 Science 91(11): 4414-23.

635 Shichen W, Wong D, Forrest K, Allen A, Chao S, Huang BE, Maccaferri M et al (2014)

636 Characterization of Polyploid Wheat Genomic Diversity Using a High-Density 90,000 Single

637 Nucleotide Polymorphism Array. Plant Biotechnology Journal 12(6): 787-96.

638 Wu L, Xia X, Rosewarne GM, Zhu H, Li S, Zhang Z, He Z (2015) Stripe rust resistance gene 639 Yr18 and its suppressor gene in Chinese wheat landraces. Plant Breeding 134(6): 634-640.

640 Yates S, Mikaberidze A, Krattinger SG, Abrouk M, Hund A, Yu K, Studer B, Fouche S, Meile 641 L, Pereira D, Karisto, P et al (2019) Precision phenotyping reveals novel loci for quantitative 642 resistance to septoria tritici blotch. Plant Phenomics 2019:3285904.

643 Jianming Y, Buckler ES (2006) Genetic Association Mapping and Genome Organization of 644 Maize. Current Opinion in Biotechnology 17(2): 155-60.

645 Yu J, Pressoir G, Briggs WH, Bi IV, Yamasaki M, Doebley JF, McMullen MD et al (2006) A 646 Unified Mixed-Model Method for Association Mapping That Accounts for Multiple Levels of 647 Relatedness. Nature Genetics 38(2): 203-8.

648 Zeller FJ, Hsam SLK (1996) Chromosomal location of a gene suppressing powdery mildew 649 resistance genes Pm8 and Pm17 in common wheat (Triticum aestivum L. em. Thell.). Theoretical 650 and applied genetics 93(1-2):38-40.

651 Zhang Z, Ersoz E, Lai CQ, Todhunter RJ, Tiwari HK, Gore MA, Bradbury PJ et al (2010) Mixed 652 Linear Model Approach Adapted for Genome-Wide Association Studies. Nature Genetics 42(4): $653 \quad 355-60$. 
654 Zhan J, Linde CC, Jürgens T, Merz U, Steinebrunner F, McDonald BA (2005) Variation for 655 Neutral Markers Is Correlated with Variation for Quantitative Traits in the Plant Pathogenic 656 Fungus Mycosphaerella graminicola. Molecular Ecology 14(9): 2683-93.

657 Zhan J, Pettway RE, McDonald BA (2003) The Global Genetic Structure of the Wheat Pathogen 658 Mycosphaerella graminicola Is Characterized by High Nuclear Diversity, Low Mitochondrial 659 Diversity, Regular Recombination, and Gene Flow. Fungal Genetics and Biology 38(3): 286-97.

660 Zhong Z, Marcel TC, Hartmann FE, Ma X, Plissonneau C, Zala M, Ducasse A et al (2017) A 661 Small Secreted Protein in Zymoseptoria tritici Is Responsible for Avirulence on Wheat Cultivars 662 Carrying the Stb6 Resistance Gene. The New Phytologist 214(2): 619-31.

663 Zogg H, Horber E, Salzmann, R (1950) Bericht uber die Tatigkeit der Eidg. 664 Landwirtschaftlichen Versuchsanstalt Zurich-Oerlikon pro 1948/1949. 8. Pflanzenschutz. Annu. 665 Agric. Suisse 51:432-442

666

667 UN (2015) The World Population Prospects: 2015 Revision [Online]. Available:

668 http://www.un.org/en/development/desa/publications/world-population-prospects-2015-

669 revision.html (Accessed September 1, 2018).

670

671

672

673

674

675

676

677

678

679

680

681

682

683

684

685

686

687 


\section{Figure legends}

Fig. 1 Frequency distribution of resistance scores to septoria tritici blotch. (a) Percent leaf area covered by lesions (PLACL) and (b) Pycnidia density per $\mathrm{cm}^{2}$ of lesion among 188 Swiss wheat landraces inoculated with four Zymoseptoria tritici isolates. Raw data are shown

Fig. 2 Boxplot showing multiple comparisons among four Zymoseptoria tritici isolates for (a) percent leaf area covered by lesions (PLACL) and (b) pycnidia density per $\mathrm{cm}^{2}$ of lesion from 188 Swiss wheat landraces. The box boundaries indicate the $25^{\text {th }}$ (lower) and $75^{\text {th }}$ (upper) percentile, and the line within the box indicates the median value. The whiskers above and below the box represent the highest and lowest values, respectively

Fig. 3 Genome-wide association mapping (GWAS) for resistance to septoria tritici blotch. Manhattan plots showing SNP marker association $p$-values for (a) percent leaf area covered by lesions (PLACL) and (b) pycnidia density per $\mathrm{cm}^{2}$ of lesion among 188 Swiss wheat landraces for the Zymoseptoria tritici isolate 1E4. SNP markers are shown as dots colored according to their associated chromosomes. The red line indicates the Bonferroni threshold at 5\% significance level $\left(-\log _{10}(P)=5.27\right)$. The SNP above the Bonferroni threshold is labelled with a specific SNP identifier

708

709 Fig. 4 Boxplots showing resistance values for (a) percent leaf area covered by lesions (PLACL) and (b) pycnidia density per $\mathrm{cm}^{2}$ of lesion among 188 Swiss wheat landraces carrying either the resistance

(T) or susceptible

(C) allele at the SNP 
Excalibur_c34649 556 . The box boundaries indicate the $25^{\text {th }}$ (lower) and $75^{\text {th }}$ (upper) percentile, and the line within the box indicates the median value. The whiskers above and below the box represent the highest and lowest values, respectively

716 Fig. 5 Schematic representation of sequence alignment of Stb6 alleles. The DNA sequence

Fig. 6 Phylogenetic relationships using Neighbor-Joining method among the identified Stb6 alignment of different allelic forms of the Stb6 gene isolated from 178 Swiss wheat landraces together with the resistance Stb6-1 allele (KY_485190.1) and the susceptible Stb6-3 allele (KY_485192.1) as references is shown. Only the nucleotide sequence alignments are shown. The domain regions of the reference allele are illustrated at the bottom in the yellow box. The unit scale indicates the nucleotide position in base pairs. The black lines inside the grey rectangles indicate nucleotide polymorphisms compared to the reference allele Stb6-1. Numbers within brackets on the right side indicate the number of landraces carrying the allele and the number of nucleotide polymorphisms, respectively. The number in the parenthesis on the left side is a representative landrace identifier from each group of alleles alleles. Phylogenetic analysis was performed using $S t b 6$ allele sequences identified among Swiss wheat landraces together with previously reported Stb6 allele sequences (black colored) from Saintenac et al. (2018). Two homoeologous sequences of the resistance Stb61 allele (KY_485190.1) on wheat chromosome 3B and 3D were form the Chinese Spring RefSeq v1.0. A distantly related wall-associated kinase (XM_020327419.1) in Aegilops tauschii was used as an outgroup. Bootstrap values (1,000 replications) are shown at the 
branch nodes. The alleles identified in Swiss wheat landraces are labelled in green and blue

738 Fig. 7 Boxplot showing the phenotypic distribution of (a) percent leaf area covered by lesions (PLACL) and (b) pycnidia density per $\mathrm{cm}^{2}$ of lesion for each of the alleles found among 178 Swiss wheat landraces. The resistant and susceptible landrace groups correspond to the reference resistance allele $S t b 6-1$ and susceptible allele $S t b 6-3$, respectively. The box boundaries indicate the $25^{\text {th }}$ (lower) and $75^{\text {th }}$ (upper) percentile, and the line within the box indicates the median value. The whiskers above and below the box represent the highest and lowest values, respectively 


\section{Supplementary information}

759

776 Supplementary Fig. S3 Representative electrophoresis gel picture of molecular screening for Stb6 alleles in Swiss wheat landraces. Molecular screening was performed using previously

Supplementary Fig. S1 Phenotypic correlation between percent leaf area covered by lesions (PLACL) and pycnidia density per $\mathrm{cm}^{2}$ of lesion among 188 Swiss wheat landraces for four Zymoseptoria tritici isolates. Raw data were used to calculate the correlations

Supplementary Fig. S2 Kinship analysis in GAPIT using the SNP dataset on 188 Swiss wheat landraces. Top left, the distribution of estimated kinship values follows a normal distribution (turquoise curve). The heatmap shows the pairwise kinship values between each pair of landraces. The darker colour (i.e., red) indicates that two landraces have a higher genetic relationship. The dendrogram was estimated based on the kinship values reported Stb6 gene specific primers 8311F19, 8311F3, 8311F16 and 8311R16, 100bp DNA ladder, and control (Chinese Spring carrying Stb6 resistance gene). 1-14 are sample 
landraces. The landraces showing the amplified product of $\sim 1.6$ kilobase pair fragment confirm the presence of the first exon of the Stb6 gene.

782

783 Supplementary Fig. S4 Sample electrophoresis gel picture for confirming the presence of novel alleles of Stb6 gene in Swiss wheat landraces. Molecular screening was performed using the reverse complement of the reverse primer $8311 \mathrm{~F} 3$ that amplifies the first exon and reverse complement of the forward primer 8311F16 that amplifies the remaining exons, 1 kilobase pair DNA ladder, resistant controls carrying the Stb6 resistance allele (KY_485190.1). 1-5 are sample landraces showing high sequence dissimilarity to the reference Stb6 resistance allele 


\section{Figures}

A
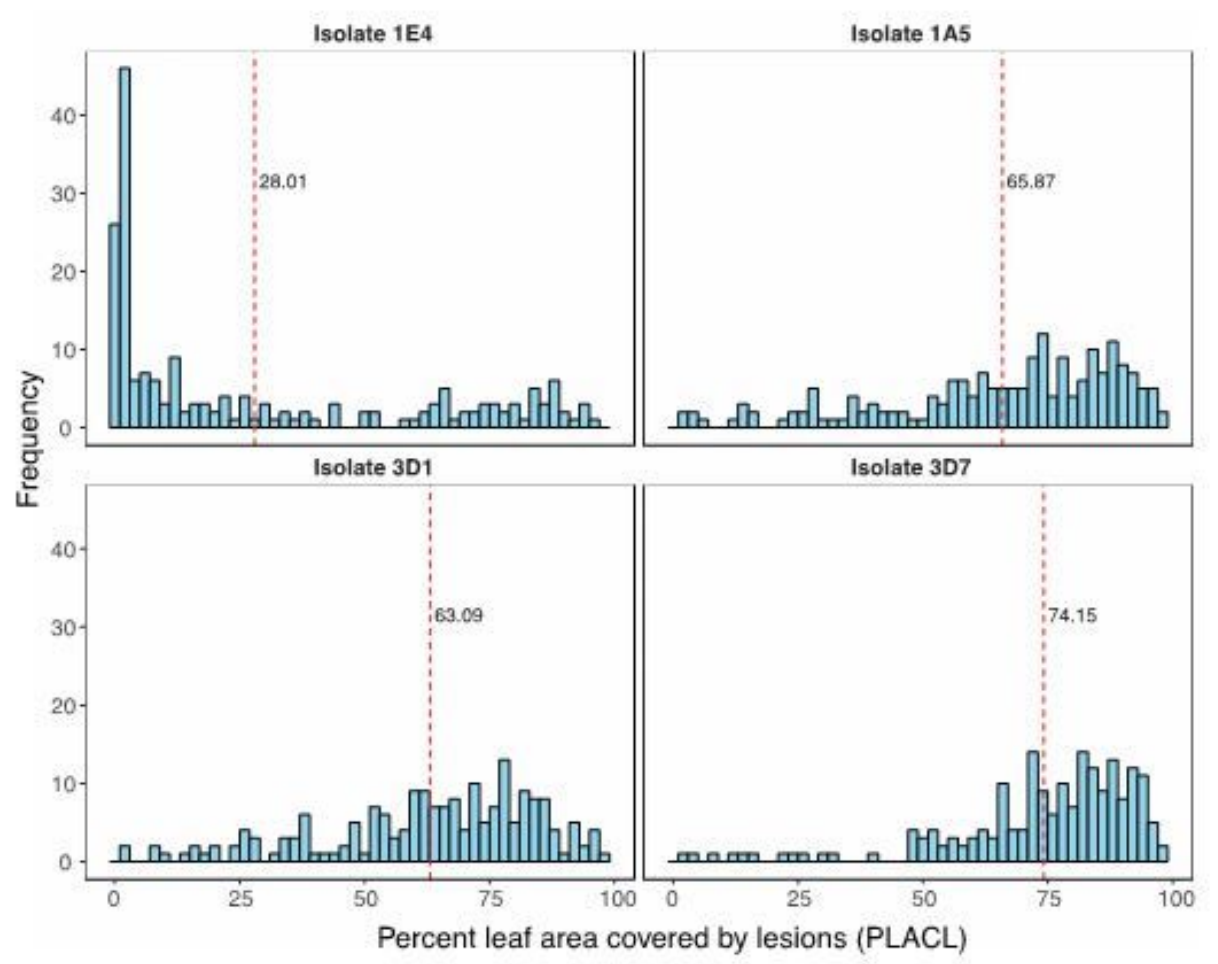

B

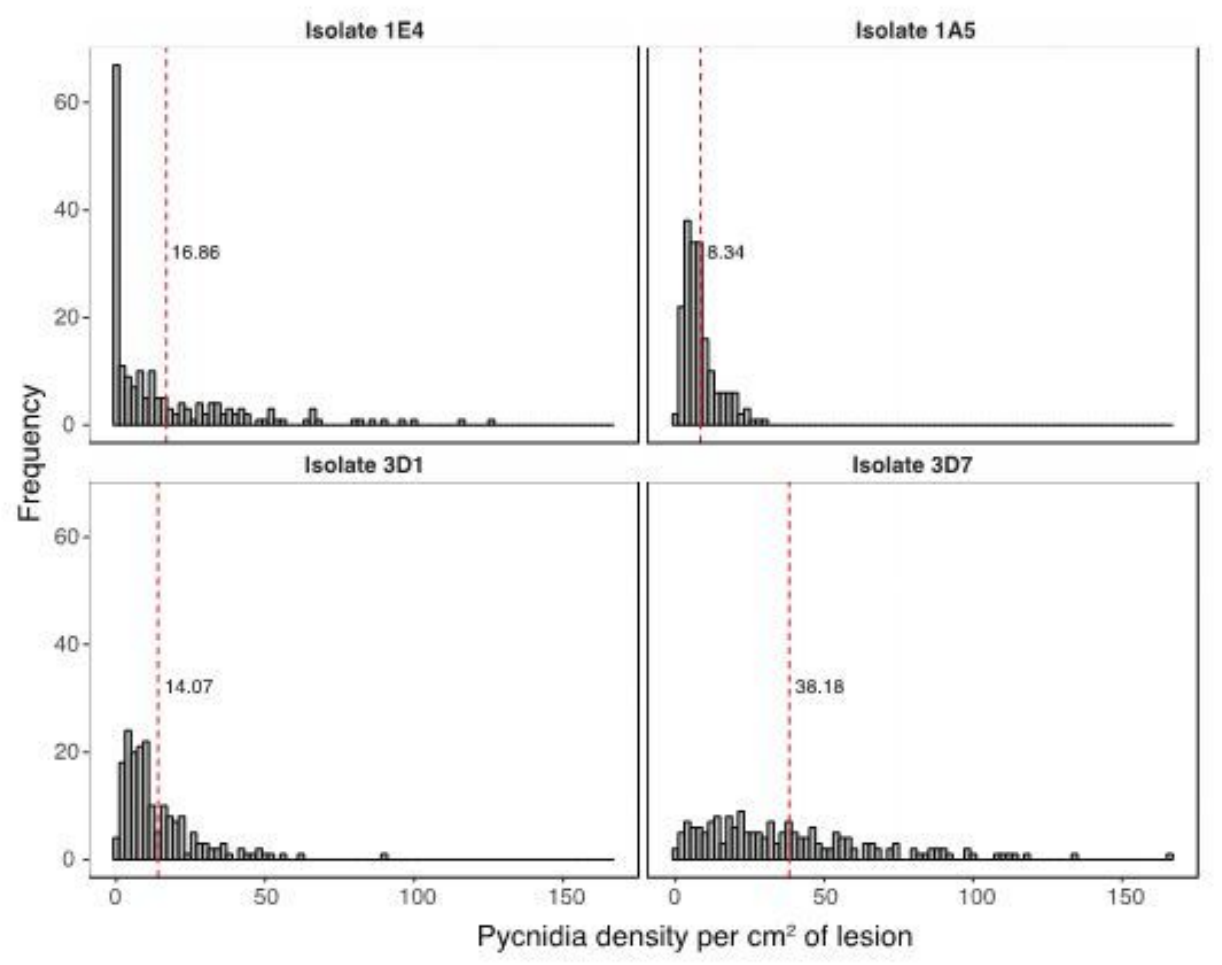

\section{Figure 1}

Frequency distribution of resistance scores to septoria tritici blotch. (a) Percent leaf area covered by lesions (PLACL) and (b) Pycnidia density per $\mathrm{cm} 2$ of lesion among 188 Swiss wheat landraces inoculated with four Zymoseptoria tritici isolates. Raw data are shown 
A

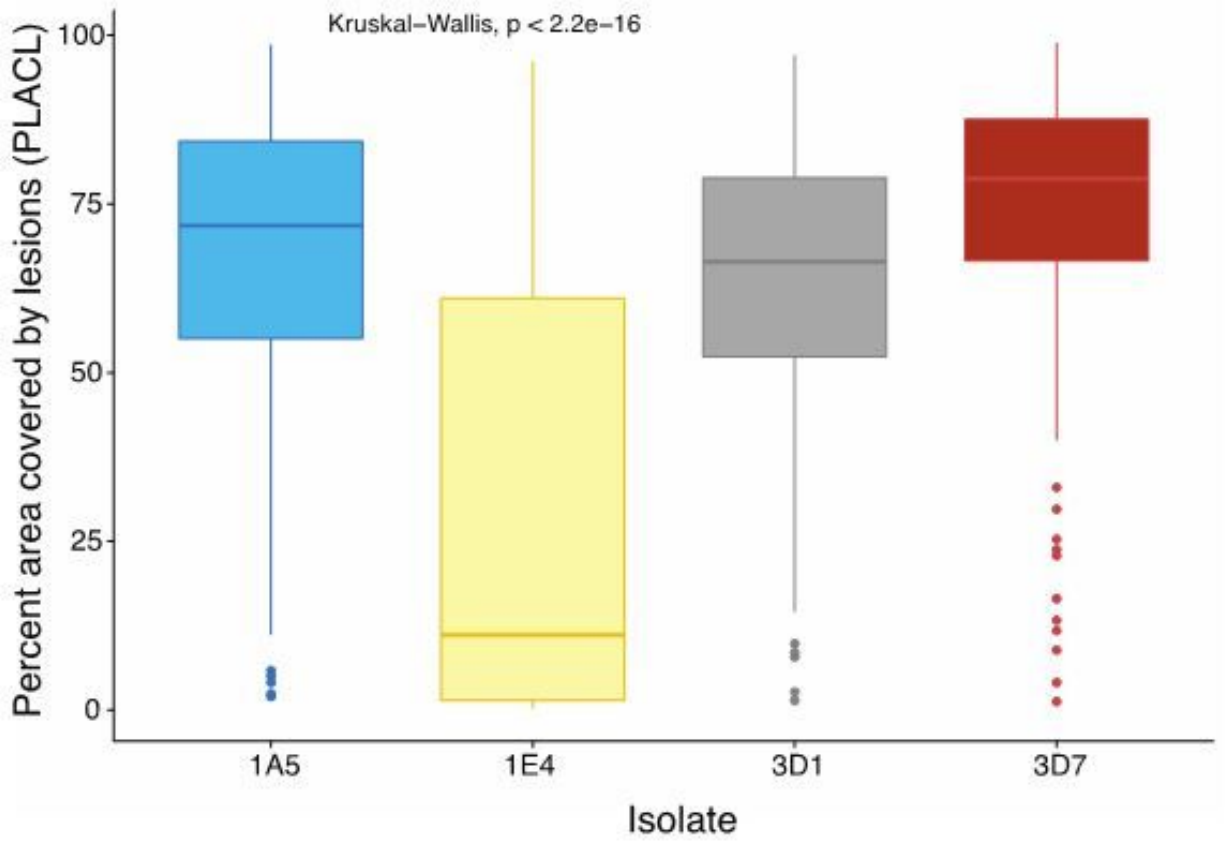

B

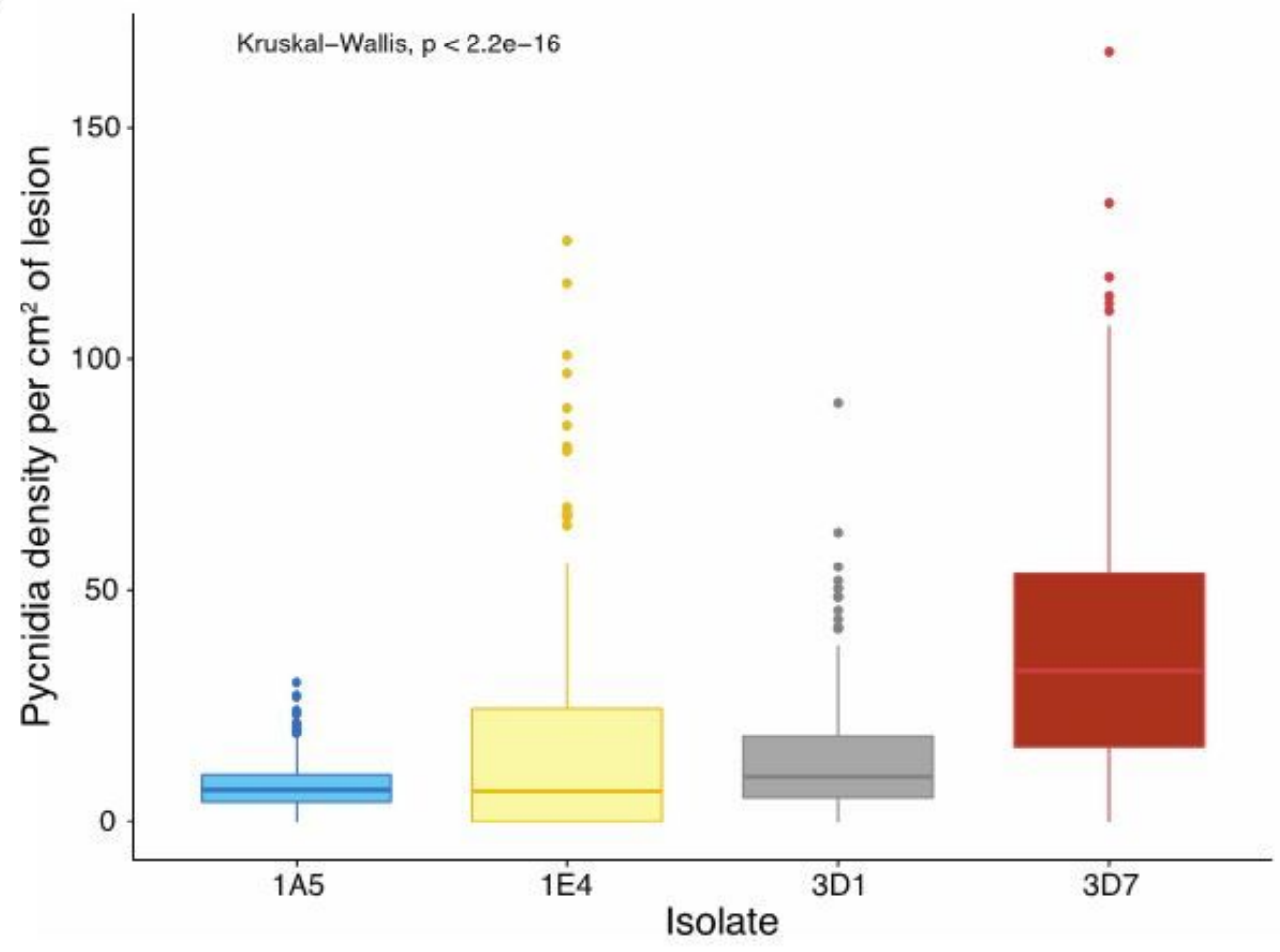

Figure 2

Boxplot showing multiple comparisons among four Zymoseptoria tritici isolates for (a) percent leaf area covered by lesions (PLACL) and (b) pycnidia density per cm2 of lesion from 188 Swiss wheat landraces. The box boundaries indicate the 25th (lower) and 75th (upper) percentile, and the line within the box indicates the median value. The whiskers above and below the box represent the highest and lowest values, respectively 

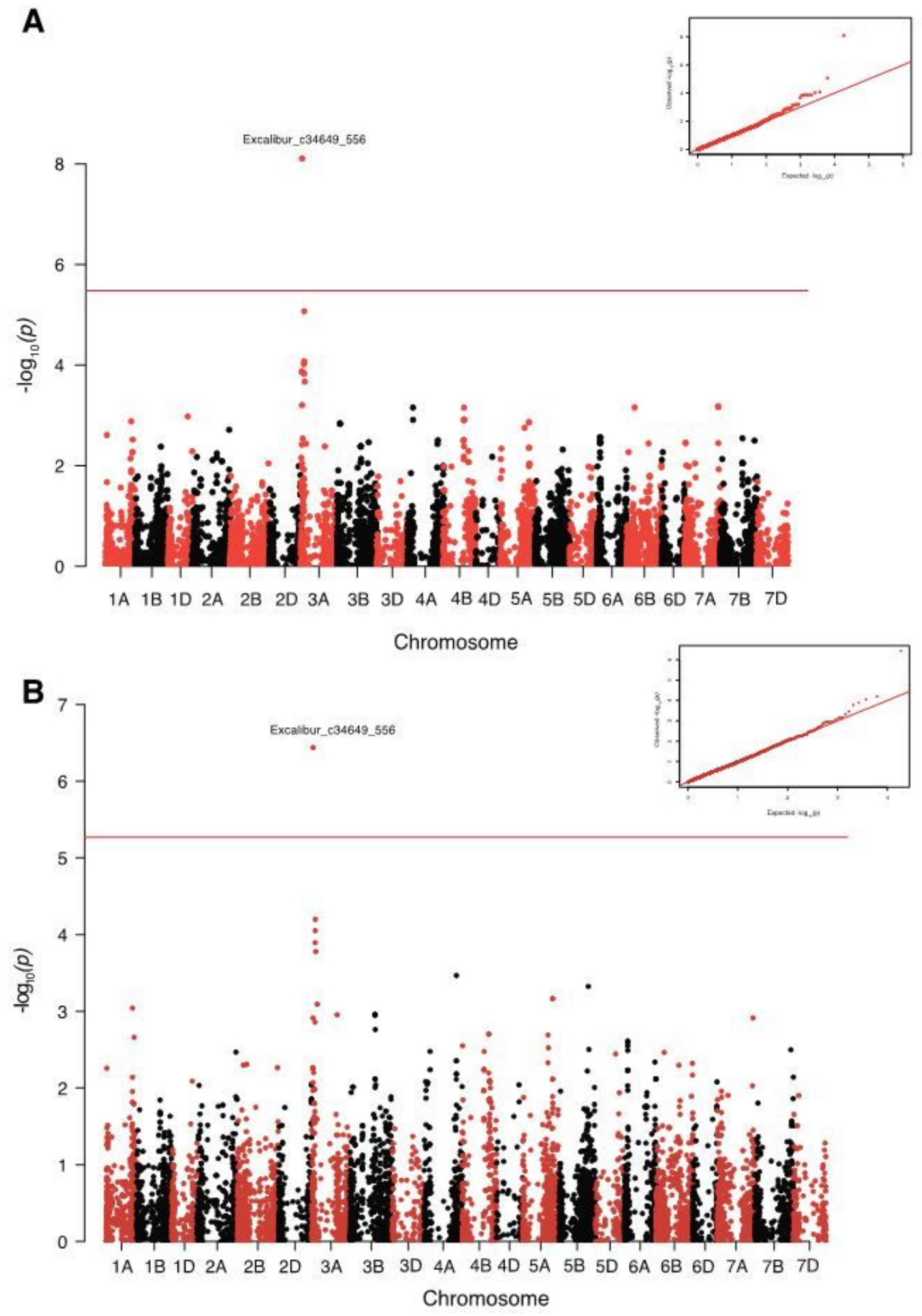

Figure 3

Genome-wide association mapping (GWAS) for resistance to septoria tritici blotch. Manhattan plots showing SNP marker association p-values for (a) percent leaf area covered by lesions (PLACL) and (b) pycnidia density per $\mathrm{cm} 2$ of lesion among 188 Swiss wheat landraces for the Zymoseptoria tritici isolate 1E4. SNP markers are shown as dots colored according to their associated chromosomes. The red line 
indicates the Bonferroni threshold at $5 \%$ significance level $(-\log 10(P)=5.27)$. The SNP above the Bonferroni threshold is labelled with a specific SNP identifier

\section{A}

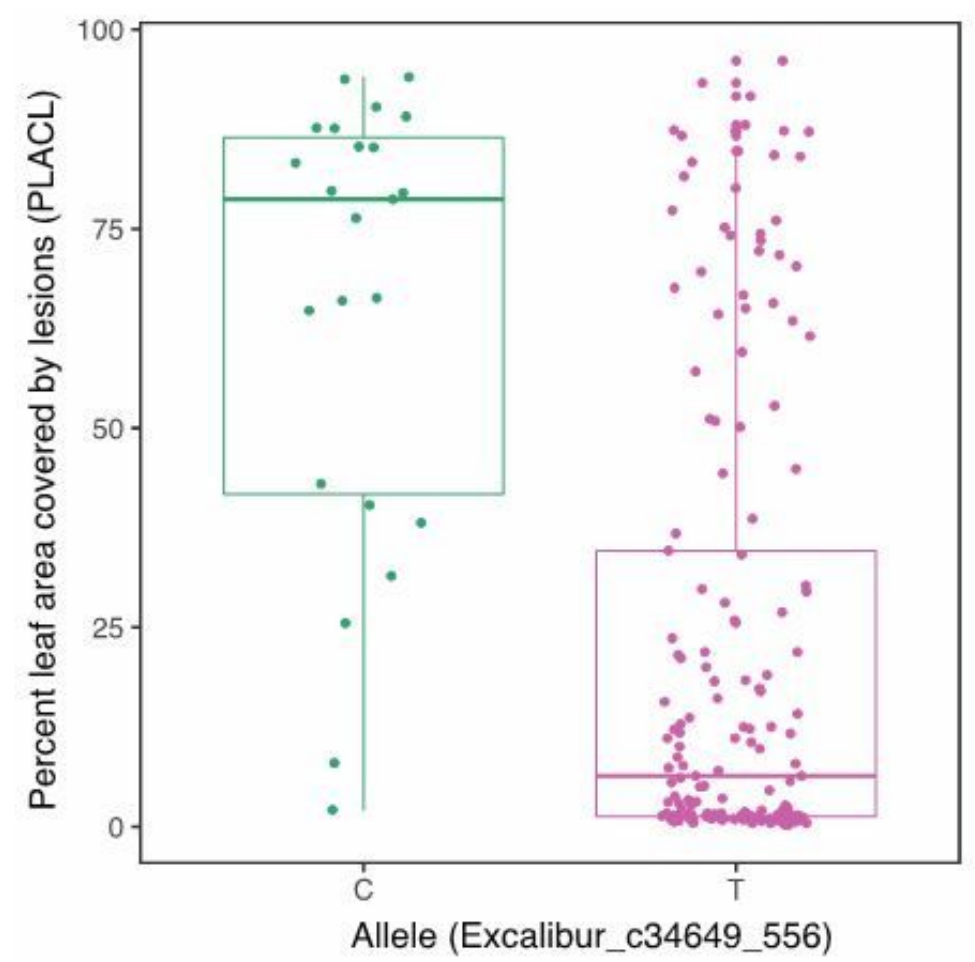

B

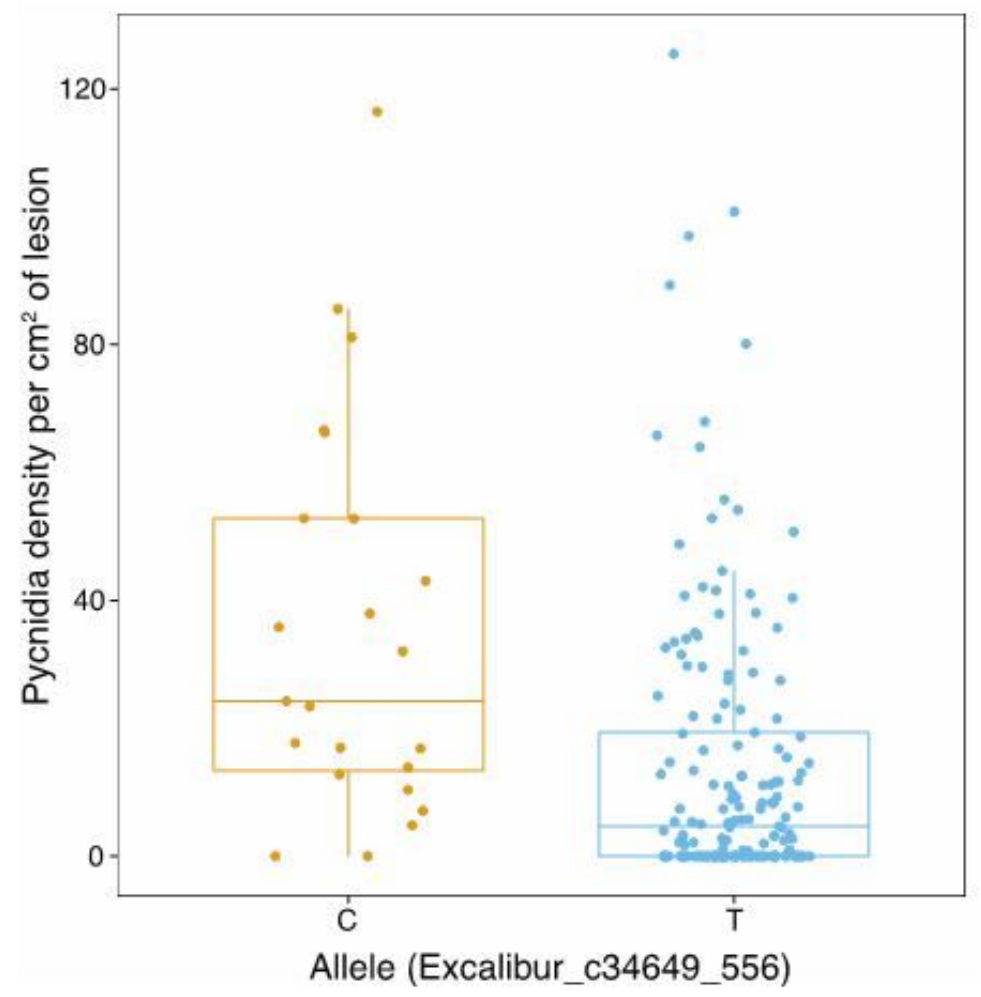

Figure 4

Boxplots showing resistance values for (a) percent leaf area covered by lesions (PLACL) and (b) pycnidia density per $\mathrm{cm} 2$ of lesion among 188 Swiss wheat landraces carrying either the resistance $(T)$ or susceptible (C) allele at the SNP Excalibur_c34649_556. The box boundaries indicate the 25th (lower) and 
75th (upper) percentile, and the line within the box indicates the median value. The whiskers above and below the box represent the highest and lowest values, respectively

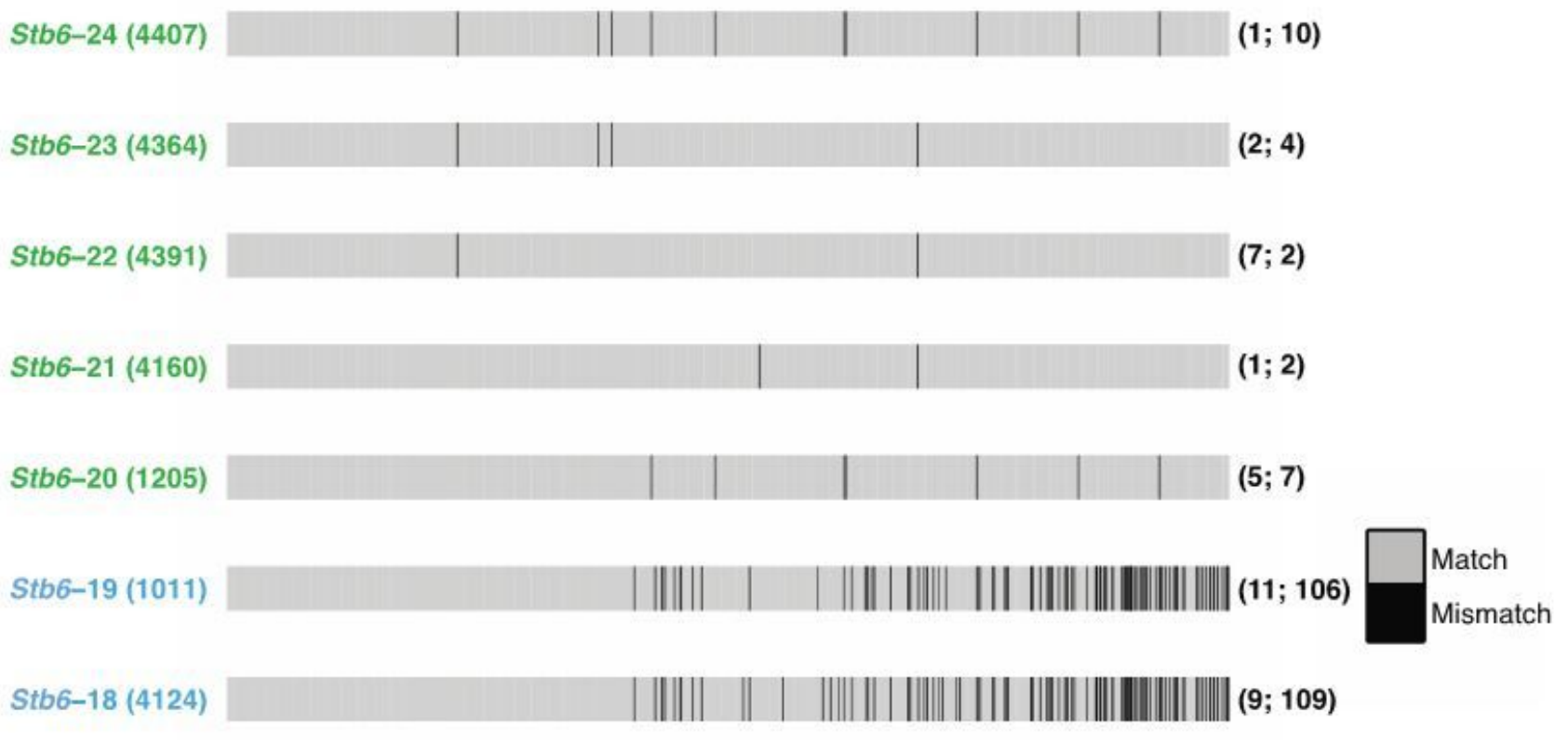

\section{Stb6-3}

Resistant_landrace (1033)

$(118 ; 0)$

Stb6-1 (reference allele)

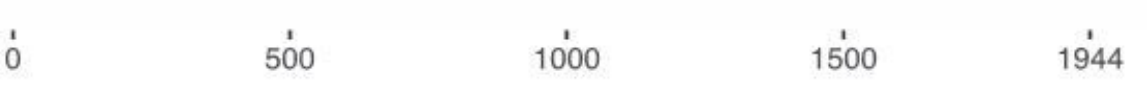

Nucleotide position in sequence (bp)

\begin{tabular}{l||l|l|l|l|}
\hline SP & GUB WAK & TM & S/T Kinase & \\
\hline SP $=$ Signal peptide
\end{tabular}
TM= Transmembrane region
GUB WAK $=$ wall-associated receptor-kinase galacturonan-binding domain

\section{Figure 5}

Schematic representation of sequence alignment of Stb6 alleles. The DNA sequence alignment of different allelic forms of the Stb6 gene isolated from 178 Swiss wheat landraces together with the resistance Stb6-1 allele (KY_485190.1) and the susceptible Stb6-3 allele (KY_485192.1) as references is shown. Only the nucleotide sequence alignments are shown. The domain regions of the reference allele are illustrated at the bottom in the yellow box. The unit scale indicates the nucleotide position in base pairs. The black lines inside the grey rectangles indicate nucleotide polymorphisms compared to the reference allele Stb6-1. Numbers within brackets on the right side indicate the number of landraces 
carrying the allele and the number of nucleotide polymorphisms, respectively. The number in the parenthesis on the left side is a representative landrace identifier from each group of alleles

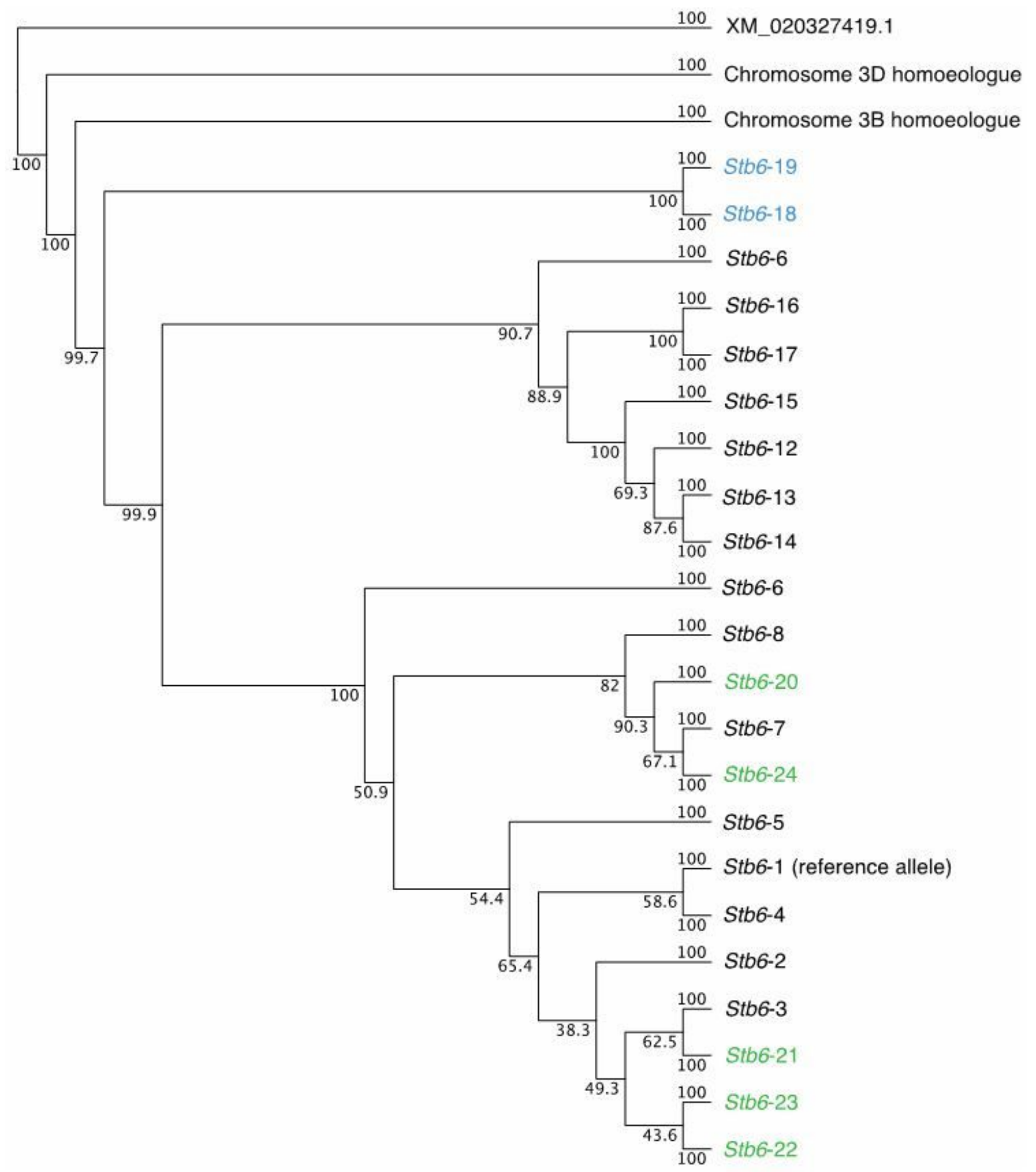

\section{Figure 6}

Phylogenetic relationships using Neighbor-Joining method among the identified Stb6 alleles. Phylogenetic analysis was performed using Stb6 allele sequences identified among Swiss wheat landraces together with previously reported Stb6 allele sequences (black colored) from Saintenac et al. 
(2018). Two homoeologous sequences of the resistance Stb6-1 allele (KY_485190.1) on wheat chromosome 3B and 3D were form the Chinese Spring RefSeq v1.0. A distantly related wall-associated kinase (XM_020327419.1) in Aegilops tauschii was used as an outgroup. Bootstrap values $(1,000$ replications) are shown at the branch nodes. The alleles identified in Swiss wheat landraces are labelled in green and blue
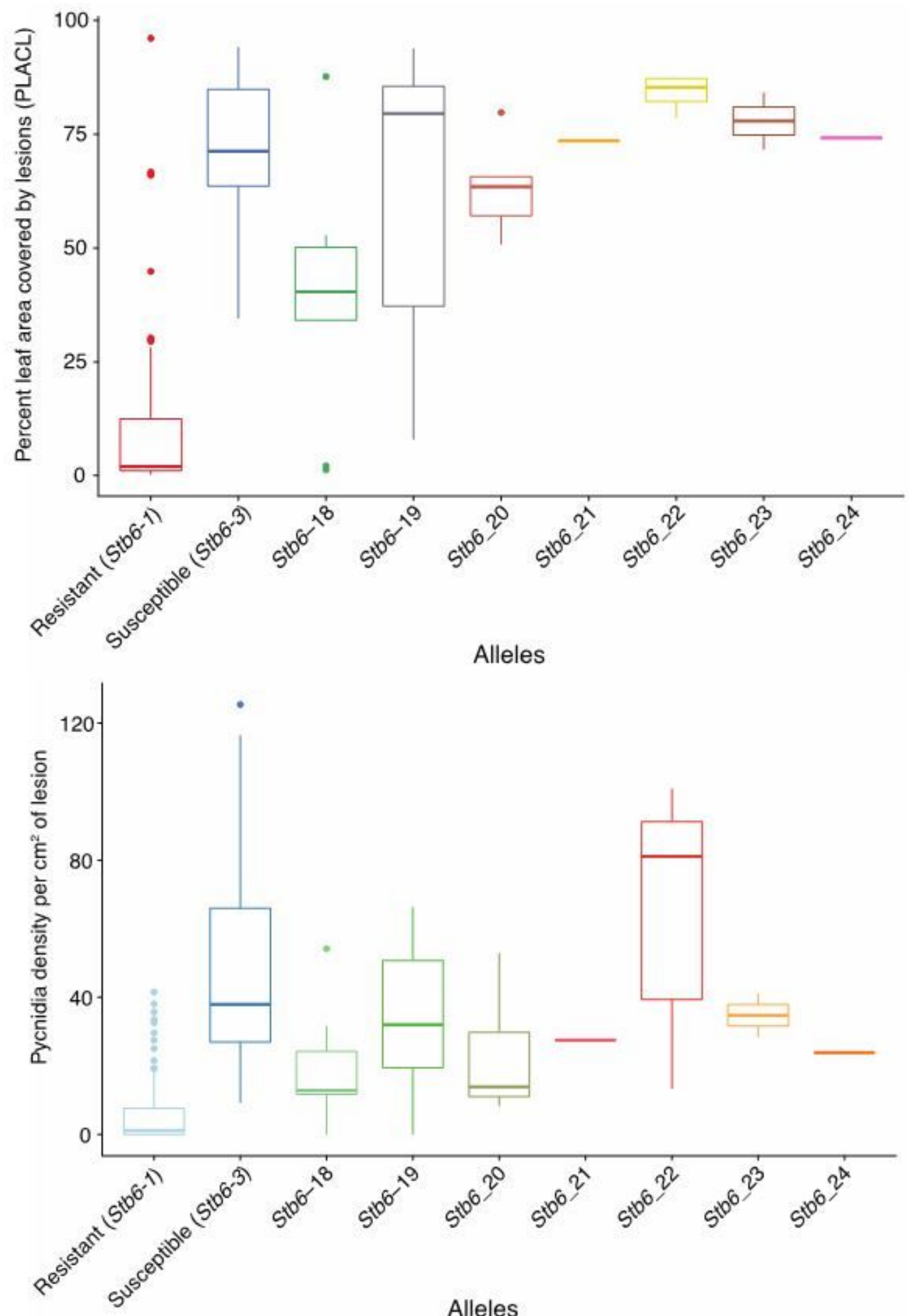

Figure 7 
Boxplot showing the phenotypic distribution of (a) percent leaf area covered by lesions (PLACL) and (b) pycnidia density per $\mathrm{cm} 2$ of lesion for each of the alleles found among 178 Swiss wheat landraces. The resistant and susceptible landrace groups correspond to the reference resistance allele Stb6-1 and susceptible allele Stb6-3, respectively. The box boundaries indicate the 25th (lower) and 75th (upper) percentile, and the line within the box indicates the median value. The whiskers above and below the box represent the highest and lowest values, respectively

\section{Supplementary Files}

This is a list of supplementary files associated with this preprint. Click to download.

- SupplementaryFigS1.docx

- SupplementaryFigS2.docx

- SupplementaryFigS3.docx

- SupplementaryFigS4.docx

- SupplementaryTableS1.xlsx 